\title{
Techniques
}

\section{Automated and Manual Human Papilloma Virus in situ Hybridization and p16 Immunohistochemistry: Comparison in Metastatic Oropharyngeal Carcinoma}

\author{
Nazneen Fatima Cynthia Cohen Diane Lawson Momin T. Siddiqui
}

Department of Pathology and Laboratory Medicine, Emory University Hospital, Atlanta, Ga., USA

\section{Key Words}

Fine needle aspiration · Human papilloma virus in situ hybridization - Metastatic oropharyngeal carcinoma . p16 immunohistochemical staining

\begin{abstract}
Objectives: We compared the efficacy of automated and manual human papilloma virus (HPV) in situ hybridization (ISH) and p16 immunohistochemical staining (IHC) in fine needle aspiration (FNA) of metastatic oropharyngeal carcinoma. Study Design: A total of 41 FNA cell blocks (CB) were evaluated. HPV ISH was interpreted as positive if a minimum of one tumor cell showed punctate dot-like nuclear positivity. p16 was interpreted as positive if $\geq 70 \%$ of tumor cells showed brown nuclear and cytoplasmic staining. Results: Thirty of $41 \mathrm{CB}(73 \%)$ were positive by automated HPV ISH, 25 of $41 \mathrm{CB}(60 \%)$ with manual HPV ISH. Eighteen of $41 \mathrm{CB}$ (43\%) were positive for p16 IHC. Twelve of 41 CB (29\%) with automated HPV ISH and 2 of 41 CB (4\%) with the manual method were positive at $10 \times$ magnification. Three of $41 \mathrm{CB}$ (7\%) with automated HPV ISH and 14 of 41 CB (34\%) with the manual method were positive at $20 \times$ magnification. Fifteen of $41 \mathrm{CB}(36 \%)$ with automated HPV ISH and 9 of 41 CB (21\%) with the manual method were positive at $40-60 \times$ magnifica-
\end{abstract}

\section{KARGER}

E-Mail karger@karger.com www.karger.com/acy tion. Conclusion: Automated HPV ISH plays a more significant role in determining the HPV status in CB. However, the failure to use high magnification in the evaluation can give false-negative results.

(c) 2013 S. Karger AG, Basel

\section{Introduction}

Any palpable neck mass raises the suspicion of a hematolymphoid malignancy or metastatic carcinoma arising in the oral cavity. In the past, they were commonly misdiagnosed as branchial cleft cysts [1]. In 1882, Von Volkman [2] first proposed that malignant lesions of the lateral neck arose from remnants of the branchial cleft and were called 'branchiogenic carcinomas'. In 1950, Martin [3] argued that these tumors were metastases from a primary carcinoma in the head and neck and urged that the primary tumor site should be explored. The proportion of metastatic squamous cell carcinoma (SCC) initially diagnosed of branchial cleft origin has been reported to range from 11 to $21 \%[1,4]$.

Cystic cervical lymph node metastasis is now a welldocumented, distinctive and specific phenomenon that occurs in a subset of head and neck SCC (HNSCC). This

Correspondence to: Dr. Momin T. Siddiqui

Department of Pathology and Laboratory Medicine, Emory University Hospital 1364 Clifton Road NE, G179B

Atlanta, GA 30322 (USA)

E-Mail mtsiddi@emory.edu 
unique subset of HNSCC is seen in nonsmokers and nondrinkers and is attributed to human papilloma virus (HPV) $[5,6]$. HPV-positive tumors differ from HPVnegative tumors in respect to site, tumor differentiation, genetic changes, risk factors, risk stratification, and prognosis. According to recent evidence, high-risk HPV DNA has been found in carcinomas arising in the oropharynx predominantly from the lingual and palatine tonsils, carrying a distinct basaloid histopathology and better prognosis [7]. In contrast to oropharyngeal cancers (OPC), oral cancers and other HNSCCs infrequently harbor HPV. In 2010, Machado et al. [8] examined the prevalence of HPV infection in 92 HNSCCs (oropharynx, oral cavity and other HNSCC sites). HPV was commonly detected in OPC $(16 / 22,73 \%)$, but was uncommon in oral cavity cancers $(2 / 53,4 \%)$ and in other HNSCC subsites $(1 / 17,6 \%)$.

Strong epidemiologic and molecular data have supported HPV-16 as the most prevalent type, identified in the majority $(90 \%)$ of the HPV-positive tumors $[5,8]$. The strong association of OPC with HPV infection, mainly HPV-16 and HPV-18, is now well recognized and well reported from various studies worldwide. Determination of the HPV status is now a standard practice in the pathologic evaluation of OPC because of strong diagnostic, prognostic and therapeutic implications. Detection of HPV in cervical lymph nodes of patients with an occult primary may be used to localize the primary within the oropharynx, with a high degree of certainty $[9,10]$. The incidence of cystic lymph nodes arising from metastatic SCC of Waldeyer's ring has been reported to be as high as $33-50 \%$ [11].

There are currently no internationally accepted standards for the detection of HPV in OPC. Traditional techniques for culturing virus cannot be employed for HPV as replication is tightly linked to squamous epithelial cell differentiation with capsids being produced only in terminally differentiated squamous cells. For oropharyngeal tumors, HPV DNA has been specifically integrated into tumor cell nuclei and is transcriptionally active $[7,12]$. Molecular detection of HPV DNA is currently the gold standard for identification of HPV. Three categories of molecular assays are available based on the detection of HPV DNA: (1) a nonamplified hybridization assay that includes Southern transfer hybridization, dot blot hybridization and in situ hybridization (ISH); (2) signal amplified hybridization assays such as hybrid capture assays, and (3) a target amplification assay, such as polymerase chain reaction and in situ polymerase chain reaction.
Strong correlations have been reported between diffuse nuclear and cytoplasmic p16 immunohistochemical staining (IHC) and HPV DNA detection by ISH. p16 is considered a sensitive marker of cells with active expression of HPV E7 oncoprotein, and p16 IHC is used as a surrogate marker for high-risk HPV [13]. Fregonesi et al. [14] in 2003 demonstrated diffuse p16 positivity in 69\% of HPV-16/18 cases compared to 4\% of HPV-negative cases and $0 \%$ of HPV-6/11 cases. Various studies of lymph node metastases in HNSCC reported that p16 overexpression is a surrogate marker for oropharyngeal origin and HPV association $[9,10]$.

Determining the integration status of a virus by ISH is routinely utilized in clinical practice because of cost effectiveness and feasibility. However, the reliability of the result is dependent on individual expertise and visual evaluations that may cause interobserver discrepancy. In the current study, we have addressed three important issues related to HPV ISH efficacy and efficiency. We compared automated HPV ISH with the Enzo high-risk probe to results by manual HPV ISH with the Dako high-risk probe. ISH results were compared to those by p16 IHC. We also analyzed the use of different microscope magnifications in the interpretation of HPV ISH results.

\section{Material and Methods}

A total of 41 OPC cell blocks (CB) were evaluated with automated HPV ISH utilizing the Enzo probe, the manual HPV ISH with the Dako probe, and p16 IHC.

\section{Automated ISH}

All steps were performed on the Leica Bond III or the Bond MaX automated system (Leica, Bannockburn, Ill., USA). Sections $(5 \mu \mathrm{m})$ of formalin-fixed, paraffin-embedded CB were deparaffinized and proteolytically digested with proteinase $\mathrm{K}$ for $10 \mathrm{~min}$. The probe [PathoGene ${ }^{\circledR}$ HPV Type 16/18 (Enzo Life Sciences Cat. No. ENZ-32886, Plymouth Meeting, Pa., USA), a ready-to-use cocktail of biotin-labeled HPV-16 and HPV-18-specific probes in buffered formamide and hybridization enhancers, diluted 1/30 in hydration solution] was applied to the slides, denatured for 10 min at $95^{\circ} \mathrm{C}$, hybridized for $4 \mathrm{~h}$ at $37^{\circ} \mathrm{C}$, incubated with primary streptavidin-horseradish peroxidase (HRP; GenPoint kit) for 15 min, biotinyl tyramide (GenPoint Tyramide Signal Amplification System; Dako Cat. No. K0620) for 15 min, secondary streptavidinHRP (GenPoint kit) for $15 \mathrm{~min}, 3,3$-diaminobenzidine (DAB) for $10 \mathrm{~min}$ and hematoxylin as a counterstain for $10 \mathrm{~min}$. These incubations were performed at room temperature; between incubations, sections were washed with Tris-buffered saline (TBS; Bond Wash Solution). Coverslipping was performed using the TissueTek SCA (Sakura Finetek USA, Inc., Torrance, Calif., USA) coverslipper. 


\section{Manual ISH}

CB sections $(5 \mu \mathrm{m})$ of formalin-fixed, paraffin-embedded CB were tested for the presence of HPV using the GenPoint Tyramide Signal Amplification System for Biotinylated Probes (Cat. No. code K0620). The preparation and staining steps were performed manually. Sections were deparaffinized and rehydrated to deionized water. Following a water rinse, tissues were antigen retrieved in citrate buffer (code S1700), pH 6, using an electric pressure cooker for $3 \mathrm{~min}$ at $12-15$ pounds per square inch, followed by cooling at room temperature for $20 \mathrm{~min}$. Slides were rinsed in deionized water, digested with proteinase $\mathrm{K}$, rinsed and then immersed in $0.3 \%$ hydrogen peroxide in methanol to quench endogenous peroxidase and streptavidin binding activity. After rinsing, slides were allowed to partially air dry to avoid dilution of the probe. $15 \mathrm{ml}$ of the probe (one drop from the vial; Dako HPV Types 16/18 Biotinylated DNA Probe, code Y1412) was applied to the CB section and coverslipped. Sections were denatured for $5 \mathrm{~min}$ at $95^{\circ} \mathrm{C}$ and hybridized overnight at $37^{\circ} \mathrm{C}$. Following hybridization, coverslips were removed; slides were rinsed in TBS with Tween 20 , and then stringently washed for 20 $\min$ at $58^{\circ} \mathrm{C}$. Subsequent staining was automated. All slides were loaded on an automated system (Dako AutoStainer plus, Dako, Carpinteria, Calif., USA) and incubated with primary streptavidin-HRP (1:400 dilution) for $30 \mathrm{~min}$, with biotinyl tyramide for $15 \mathrm{~min}$, secondary streptavidin for $15 \mathrm{~min}, \mathrm{DAB}$ as chromogen for $10 \mathrm{~min}$, and hematoxylin as counterstain for $1 \mathrm{~min}$. These incubations were performed at room temperature; between incubations, sections were rinsed with TBS with Tween 20. Coverslipping was performed using the Tissue-Tek SCA (Sakura Finetek) coverslipper.

\section{ISH Interpretation}

For both automated and manual ISH, a known positive control (HPV-positive oropharyngeal carcinoma) was included in each run. Each patient slide and the positive control were stained together with DNA and negative controls (no probe), respectively. Ten CB from lung SCC were studied as negative controls since they are negative for HPV, to facilitate statistical analysis.

HPV ISH was interpreted as positive if a minimum of one tumor cell showed brown punctate dot-like nuclear positivity. Punctate dot-like nuclear positivity observed with low, intermediate or high magnifications $(\times 10, \times 20$ or $\times 40-60)$ was assigned as $3+, 2+$ and $1+$, respectively. The DNA-positive control shows brown nuclear stain; the negative control has no nuclear staining.

\section{p16 Immunohistochemistry}

Sections $(5 \mu \mathrm{m})$ were deparaffinized and rehydrated to deionized water. Antigen retrieval was performed in citrate buffer (pH 6.0), using an electric pressure cooker for $3 \mathrm{~min}$ at $12-15$ pounds per square inch $\left(\right.$ at $\left.120^{\circ} \mathrm{C}\right)$, and cooled for $10 \mathrm{~min}$ prior to immunostaining. All slides were loaded onto an automated system (Dako AutoStainer plus) and exposed to 3\% hydrogen peroxide for $5 \mathrm{~min}$, incubated with monoclonal pl6INK4a (E6H4; MTM Laboratory, Westborough, Mass., USA; prediluted) for $30 \mathrm{~min}$, with labeled polymer (Envision1 + dual link) for $30 \mathrm{~min}, \mathrm{DAB}$ chromogen for $5 \mathrm{~min}$ and hematoxylin as counterstain for $5 \mathrm{~min}$. These incubations were performed at room temperature; between incubations, sections were washed with TBS. Coverslipping was performed using the Tissue Tek SCA (Sakura Finetek) coverslipper.

Human Papilloma Virus in situ Hybridization
Table 1. Frequency of ISH and IHC-positive results in CB

\begin{tabular}{llll}
\hline & $\begin{array}{l}\text { HPV ISH } \\
\text { (automated) }\end{array}$ & $\begin{array}{l}\text { HPV ISH } \\
\text { (manual) }\end{array}$ & $\begin{array}{l}\text { p16 } \\
\text { IHC }\end{array}$ \\
\hline CB & $30 / 41(73 \%)$ & $25 / 41(60 \%)$ & $18 / 41(43 \%)$ \\
\hline
\end{tabular}

Table 2. Statistical analysis of CB of HPV high-risk automated and manual ISH and p16 IHC in 41 oropharyngeal SCC

\begin{tabular}{llllll}
\hline & $\begin{array}{l}\text { Sensi- } \\
\text { tivity }\end{array}$ & $\begin{array}{l}\text { Speci- } \\
\text { ficity }\end{array}$ & PPV & NPV & $\begin{array}{l}\text { Accu- } \\
\text { racy }\end{array}$ \\
\hline HPV ISH (automated) & 73 & 100 & 100 & 47 & 78 \\
HPV ISH (manual) & 60 & 100 & 100 & 38 & 68 \\
p16 IHC & 43 & 100 & 100 & 30 & 54 \\
\hline
\end{tabular}

Data are given as percentages. $\mathrm{PPV}=$ Positive predictive value; $\mathrm{NPV}=$ negative predictive value.

Table 3. Role of magnification in the visual evaluation of manual and automated HPV ISH in metastatic oropharyngeal carcinoma

\begin{tabular}{llll}
\hline $\begin{array}{l}\text { HPV ISH } \\
\text { positive }\end{array}$ & $\begin{array}{l}\times 10 \\
3+\end{array}$ & $\begin{array}{l}\times 20 \\
2+\end{array}$ & $\begin{array}{l}\times 40-60 \\
1+\end{array}$ \\
\hline $\begin{array}{l}\text { Automated } \\
\text { Manual }\end{array}$ & $\begin{array}{c}12 / 41(29 \%) \\
2 / 41(4 \%)\end{array}$ & $\begin{array}{c}3 / 41(7 \%) \\
14 / 41(34 \%)\end{array}$ & $\begin{array}{r}15 / 41(36 \%) \\
9 / 41(21 \%)\end{array}$ \\
\hline
\end{tabular}

Positive controls of known positive CB HPV-positive (SCC) and negative controls with primary antibody replaced with TBS were run with the study slides. p16 was interpreted as positive if $70 \%$ of tumor cells showed brown nuclear and cytoplasmic staining.

\section{Results}

Table 1 indicates the HPV ISH and p16 IHC results; table 2 gives results of the statistical analysis. Thirty of 41 CB (73\%) were positive by automated HPV ISH (fig. 1), 25 of $41 \mathrm{CB}(60 \%)$ with manual HPV ISH (fig. 2). Eighteen of $41 \mathrm{CB}(43 \%)$ cases were positive for p16 IHC (fig. 3). Twelve of 41 CB (29\%) with automated HPV ISH (fig. 1a) and 2 of $41 \mathrm{CB}(4 \%)$ with the manual method (fig. 2a) were positive at $10 \times$ magnification and were considered $3+$. Three of $41 \mathrm{CB}(7 \%)$ with automated HPV 


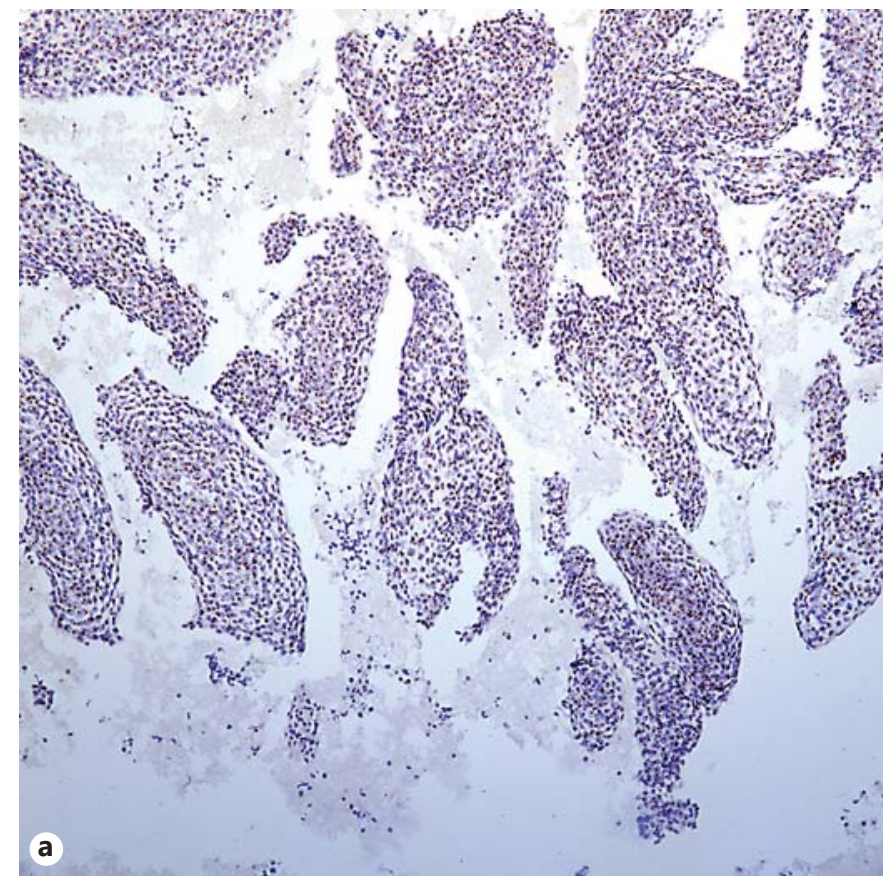

Fig. 1. Automated HPV ISH showing punctate dot-like nuclear positivity in the tumor cells at low $(\times 10 ; \mathbf{a})$, intermediate $(\times 20 ; \mathbf{b})$ and high magnification $(\times 40 ; \mathbf{c})$.

ISH (fig. 1b) and 14 of $41 \mathrm{CB}(34 \%)$ with the manual method (fig. 2 b) were positive at $20 \times$ magnification and were considered $2+$. Fifteen of $41 \mathrm{CB}(36 \%)$ with automated HPV ISH (fig. 1c) and 9 of 41 CB (21\%) with the manual method (fig. 2 c) were positive at $40-60 \times$ magnification and were considered $1+$. Table 3 indicates the positivity of the two methods of HPV ISH at 3 different magnifications. The $10 \mathrm{CB}$ from lung SCC-negative controls were all negative for HPV ISH by both techniques and p16 staining.
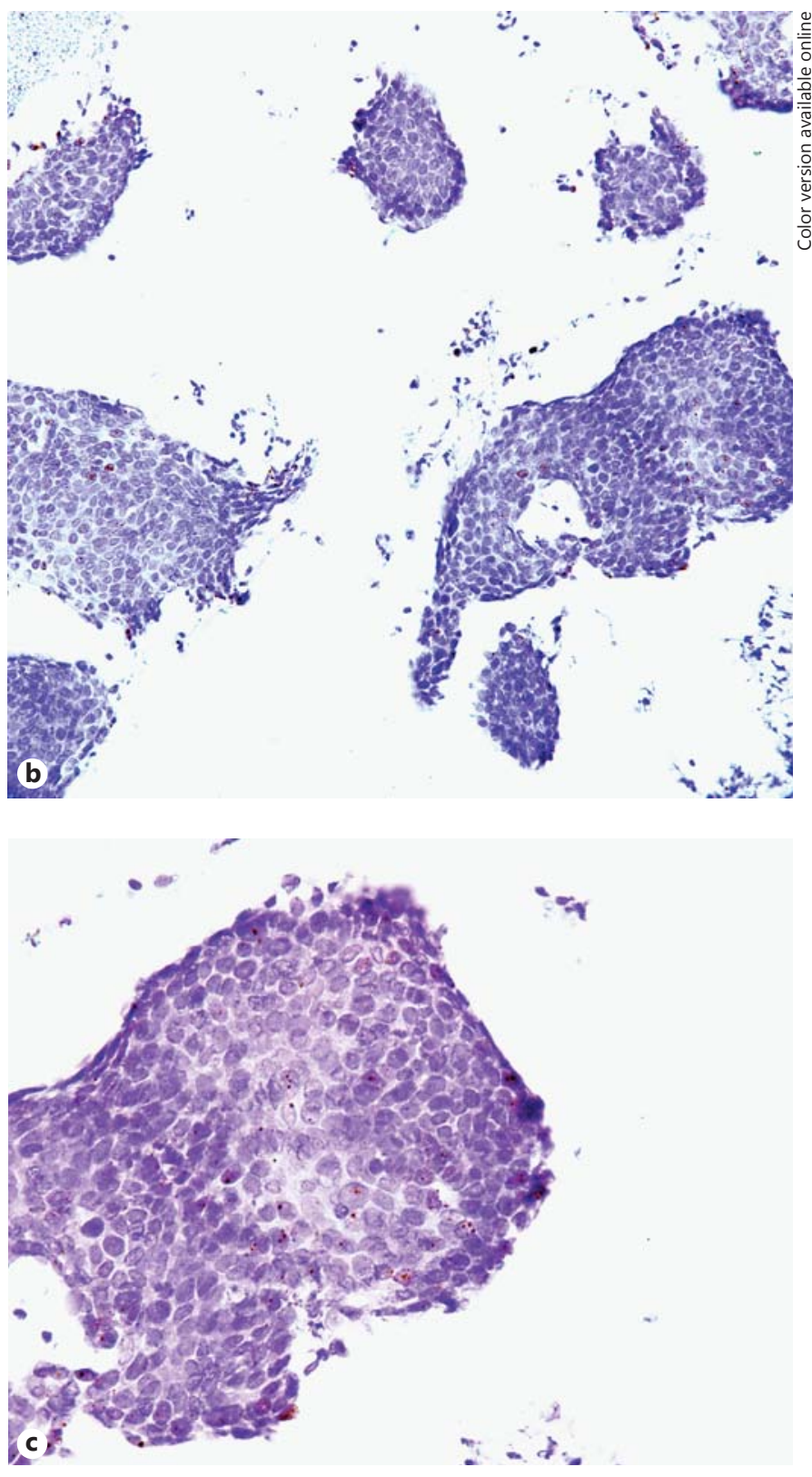

\section{Discussion}

Initial investigations of lateral neck cystic masses include imaging studies and fine needle aspiration (FNA). The simple technique of FNA has gained wide acceptance since it offers a high degree of accuracy in outpatient diagnosis of a palpable neck mass. This safe, reliable, costeffective and easy procedure can eliminate the need for an open biopsy procedure, with its potential untoward effects [15]. With the help of FNA and clinical data, the primary site of malignancy could be identified in approx- 

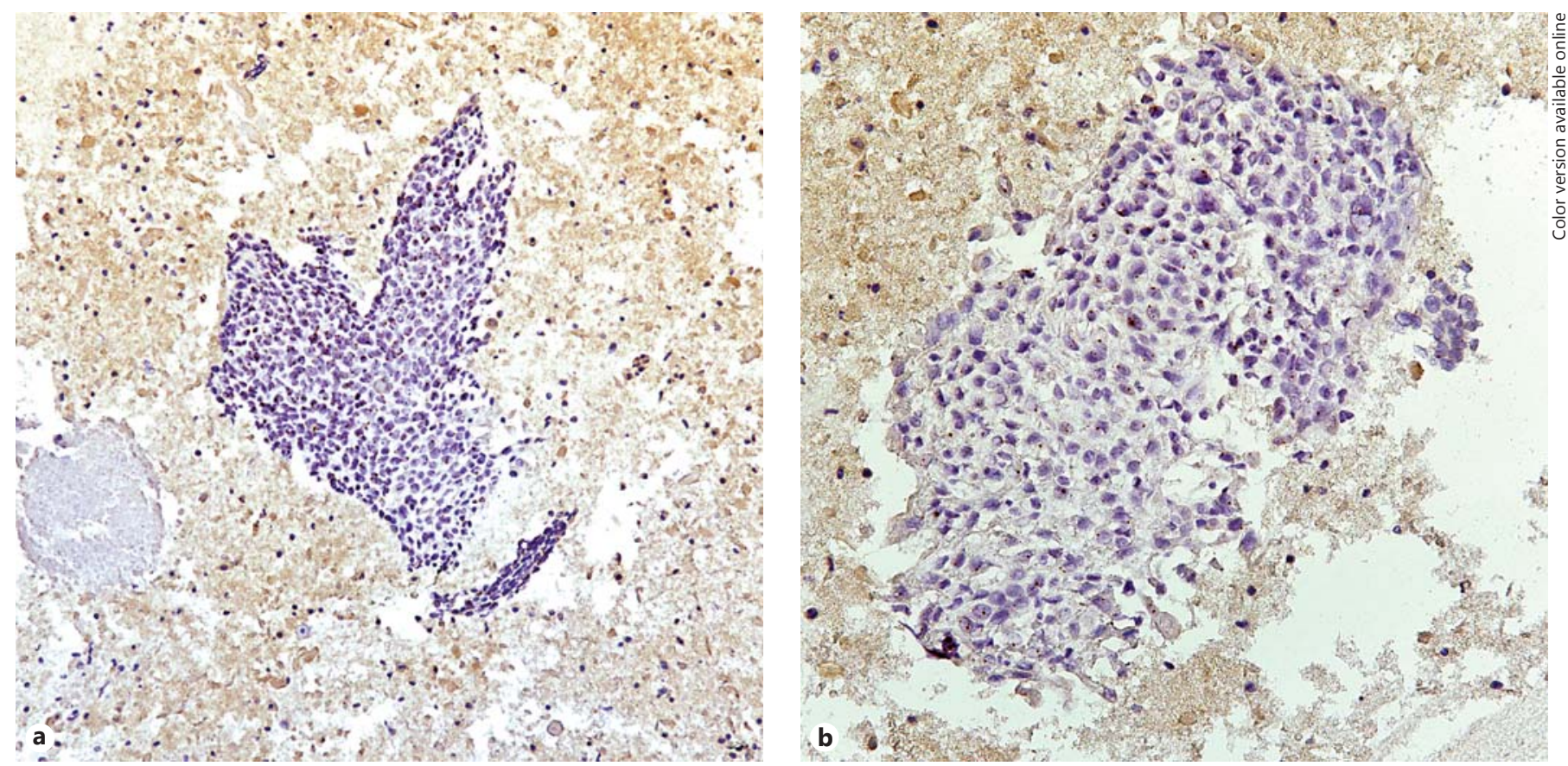

Fig. 2. Manual HPV ISH showing punctate dot-like nuclear positivity in the tumor cells at low $(\times 10 ; \mathbf{a})$, intermediate $(\times 20 ; \mathbf{b})$ and high magnification $(\times 40 ; \mathbf{c})$.

imately $90 \%$ of metastatic cases [16]. However, FNA diagnosis can be challenging in cases of cystic metastases due to hypocellularity, inflammatory cells, reactive changes, and the presence of cellular debris. This is mainly due to the nature of the lesions itself; however, it may also be due to the aspirator technique as well. Cytologic features suggesting malignancy may be lacking, resulting in a mistaken diagnosis of benign squamous cyst. Furthermore, in patients presenting without a clinically ap-

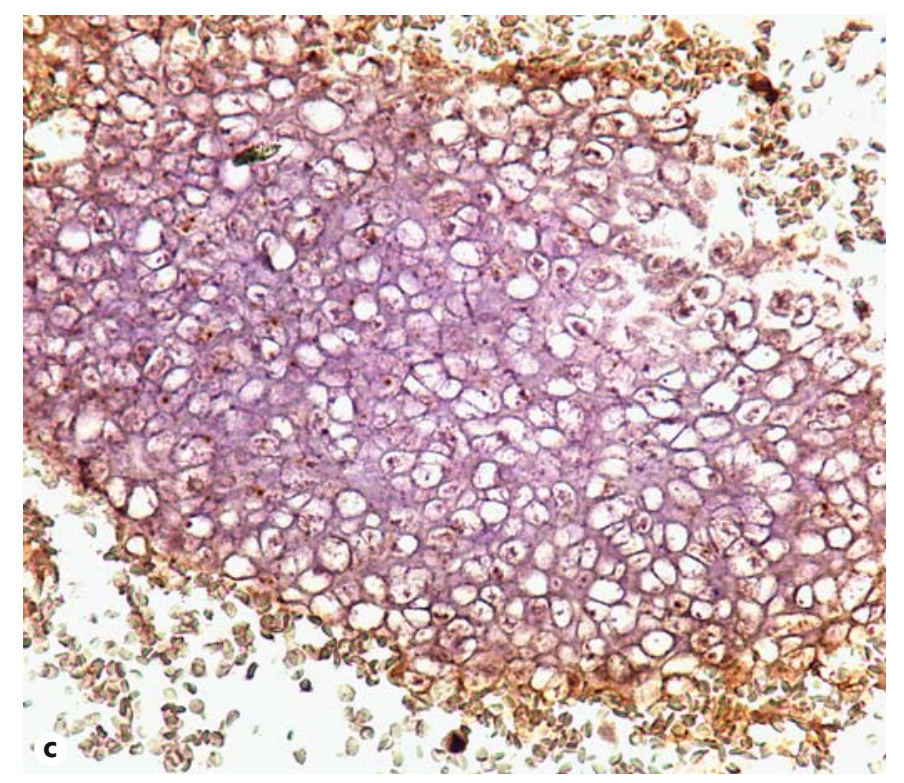

parent primary site, there are no consistent and reliable histologic features that indicate tumor origin. In the past years, the false-negative rate of FNA in the diagnosis of SCC in cystic metastases has been reported to range from 50 to $67 \%[17,18]$. In 2000, Gourin and Johnson [19] reported a false-negative rate of $63 \%$ with FNA aspirate of cystic nodes.

However, in recent years, advances in effective methods to evaluate these metastatic SCC for HPV have 


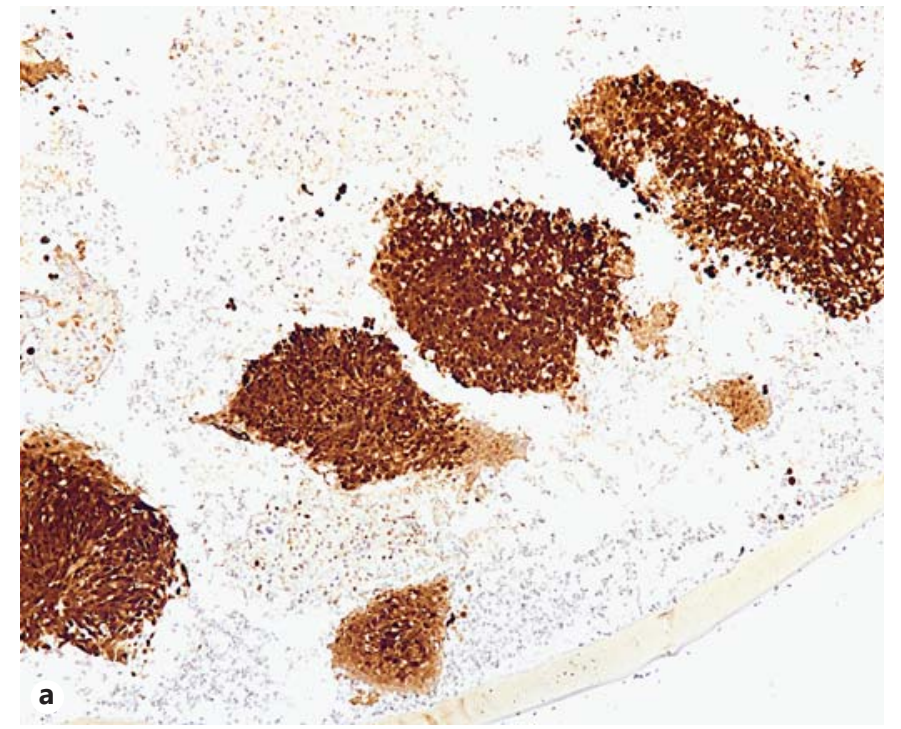

Fig. 3. p16 was interpreted as positive if $70 \%$ of tumor cells showed brown nuclear and cytoplasmic staining. Tumor cells showing p16 positivity at low $(\times 10$; $\mathbf{a})$, intermediate $(\times 20 ; \mathbf{b})$ and high magnification $(\times 40 ; \mathbf{c})$.

proven more sensitive in determining the primary site especially when this is not evident clinically [20]. In 2007, Begum et al. [21] reported the HPV-16 status in tumor cells aspirated from the necks of patients with metastatic HNSCC as a reliable indicator of origin from the oropharynx. They performed in situ hybridization for HPV-16 and p16 IHC on 77 aspirated neck masses
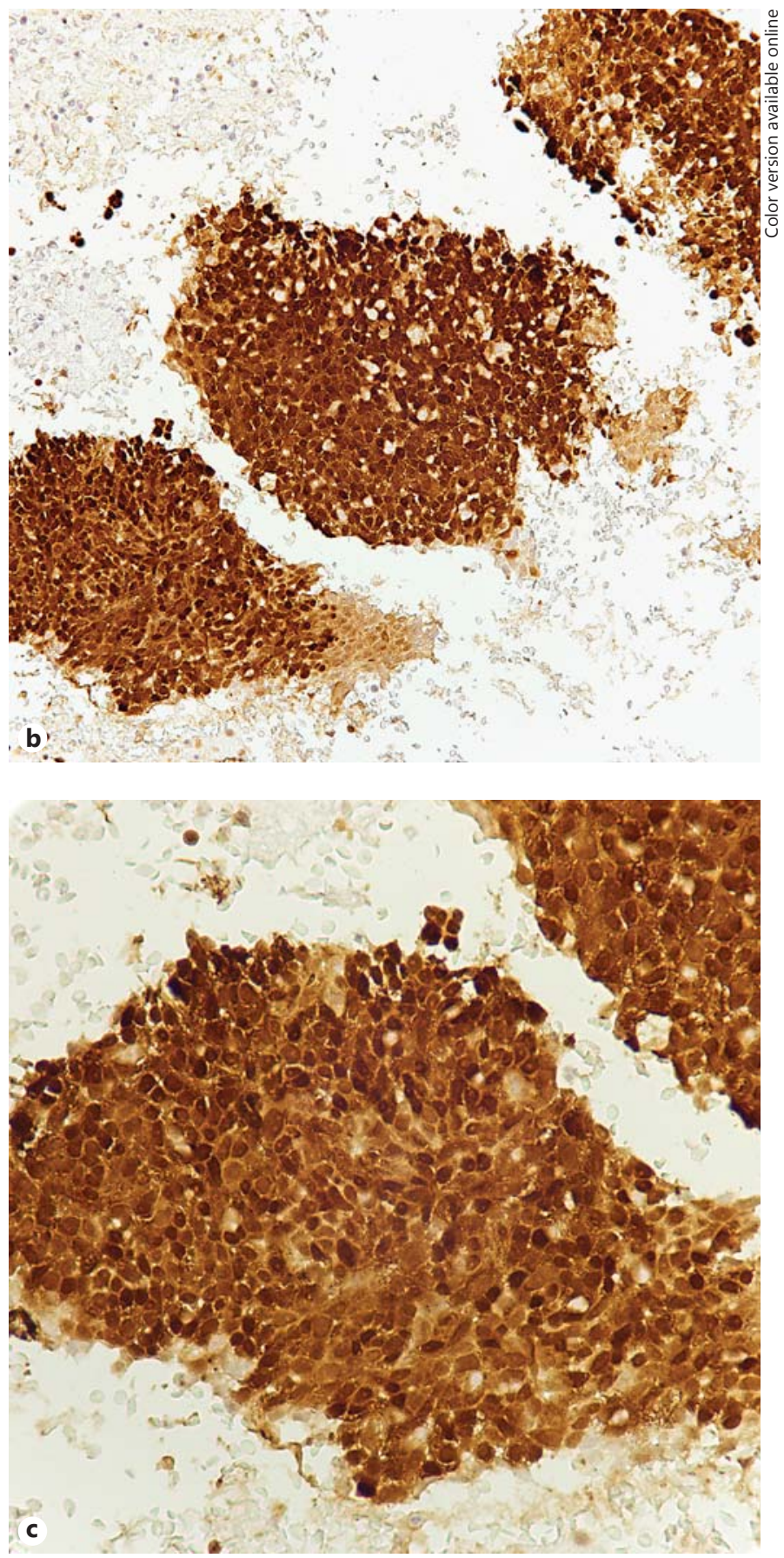

diagnosed as metastatic SCC. HPV-16 was detected in 10 of $19(52 \%)$ metastases from the oropharynx but in none of 46 metastases from other sites. HPV-16 was not detected in 2 branchial cleft cysts misdiagnosed as metastatic SCC, but it was detected in 3 of 10 (30\%) metastases from occult primary tumors. $\mathrm{p} 16$ expression was associated with the presence of HPV-16: 12 of 13 
(92\%) HPV-16-positive metastases exhibited p16 expression, whereas only 4 of 62 (6\%) HPV-16-negative metastases were p16 positive. p16 expression also correlated with the site of tumor origin: 13 of 19 (68\%) oropharyngeal metastases were p16 positive, whereas only 1 of 46 nonoropharyngeal metastases was p 16 positive.

A retrospective study conducted on 100 neck dissections concluded that cystic cervical lymph node metastases are strongly associated with HPV-related tonsillar HNSCC. Twenty patients identified with cystic lymph node metastases were analyzed for HPV DNA by ISH. Seventeen $(17 \%)$ of these patients had primary tumors arising in the palatine or lingual tonsil. HPV DNA was present in 11 of 13 patients with cystic metastases (87\%). No HPV DNA was identified in tumors from 21 patients with solid nodal metastasis [22].

Jannapureddy et al. [10] suggested a concomitant role for both ISH and IHC in the determination of the primary site. They reported that despite a higher specificity (93.1\%), HPV ISH shows a lower sensitivity (63.6\%) for detecting an oropharyngeal primary site. p16 IHC shows improved sensitivity $(81.8 \%)$ while lacking specificity $(75.8 \%)$ for oropharyngeal sites. They proposed initial p16 testing for metastatic SCC in cervical lymph nodes followed by HPV ISH for those tumors that are $\mathrm{p} 16$ positive.

\section{Conclusion}

In comparing automated HPV ISH utilizing the Enzo probe with manual HPV ISH utilizing the Dako probe and p16 IHC, we have determined that automated HPV ISH is more sensitive in determining the HPV status in $\mathrm{CB}$ as compared to the other two techniques. p16 staining is easier to recognize (fig. 3) and evaluate on tumor cells in contrast to punctate dot-like positivity seen in HPV ISH, which may be very focal and require careful evaluation at a high magnification. In addition, the cost of performing automated HPV ISH is lower than the manual methodology since the automated methodology requires less time of the technologist. The manual method requires up to $7 \mathrm{~h}$ of the time of the technologist in contrast to the automated method requiring approximately $1 \mathrm{~h}$.

The magnification power plays a critical role in the visual evaluation of HPV ISH. The dot-like punctate staining may be very focal requiring careful visual assessment of all tumor cells. Low magnification $(\times 10)$ revealed positivity in $29 \%$ of the cases with the automated technique, while the manual method showed positivity in $4 \%$ of the cases. Hence, automation provides an easy, more sensitive and less laborintensive method for performing HPV ISH. However, the failure to use high magnification $(\times 40-60)$ in the evaluation could give false-negative results in $36 \%$ of cases with the automated method and $21 \%$ with the manual method. This could confound the analysis and effect therapeutic decisions.

\section{References}

$>1$ Flanagan PM, Roland NJ, Jones AS: Cervical node metastases presenting with features of branchial cysts. J Laryngol Otol 1994;108: 1068-1071.

2 Von Volkman R: Das tiefe branchiogene Halskarcinom. Zentralbl Chir 1882;9:49-63.

73 Martin H: Untimely lymph node biopsy. Am J Surg 1961;102:17-18.

4 Granstrom G, Edstrom S: The relationship between cervical cysts and tonsillar carcinoma in adults. J Oral Maxillofac Surg 1989;47: 16-20.

5 Gillison ML, Shah KV: Human papillomavirus-associated head and neck squamous cell carcinoma: mounting evidence for an etiologic role for human papillomavirus in a subset of head and neck cancers. Curr Opin Oncol 2001;13:183-188.

-6 van Houten VM, Snijders PJ, van den Brekel MW, Kummer JA, Meijer CJ, van Leeuwen B, Denkers F, Smeele LE, Snow GB, Brakenhoff $\mathrm{RH}$ : Biological evidence that human papillo- maviruses are etiologically involved in a subgroup of head and neck squamous cell carcinomas. Int J Cancer 2001;93:232-235.

7 Gillison ML, Koch WM, Capone RB, Spafford M, Westra WH, Wu L, Zahurak ML, Daniel RW, Viglione M, Symer DE, Shah KV, Sidransky D: Evidence for a causal association between human papillomavirus and a subset of head and neck cancers. J Natl Cancer Inst 2000;92:709-720.

8 Machado J, Reis PP, Zhang T, Simpson C, Xu W, Perez-Ordonez B, Goldstein DP, Brown DH, Gilbert RW, Gullane PJ, Irish JC, KamelReid S: Low prevalence of human papillomavirus in oral cavity carcinomas. Head Neck Oncol 2010;2:6.

$\checkmark 9$ Begum S, Gillison ML, Ansari-Lari MA, Shah K, Westra WH: Detection of human papillomavirus in cervical lymph nodes: a highly effective strategy for localizing site of tumor origin. Clin Cancer Res 2003;9:64696475 .
10 Jannapureddy S, Cohen C, Lau S, Beitler JJ, Siddiqui MT: Assessing for primary oropharyngeal or nasopharyngeal squamous cell carcinoma from fine needle aspiration of cervical lymph node metastases. Diagn Cytopathol 2010;38:795-800.

11 Regauer S, Mannweiler S, Anderhuber W, et al: Cystic lymph node metastases of squamous cell carcinoma of Waldeyer's ring origin. Br J Cancer 1999;79:1437-1442.

12 Wiest T, Schwarz E, Enders C, Flechtenmacher $\mathrm{C}$, Bosch FX: Involvement of intact HPV16 E6/E7 gene expression in head and neck cancers with unaltered p53 status and perturbed $\mathrm{pRb}$ cell cycle control. Oncogene 2002;21:1510-1517.

13 Klussmann JP, Gültekin E, Weissenborn SJ, Wieland U, Dries V, Dienes HP, Eckel HE, Pfister HJ, Fuchs PG: Expression of p16 protein identifies a distinct entity of tonsillar carcinomas associated with human papillomavirus. Am J Pathol 2003;162:747-753.
Human Papilloma Virus in situ Hybridization 
14 Fregonesi PA, Teresa DB, Duarte RA, Neto CB, de Oliveira MR, Soares CP: p16INK4a immunohistochemical overexpression in premalignant and malignant oral lesions infected with human papillomavirus. J Histochem Cytochem 2003;51:1291-1297.

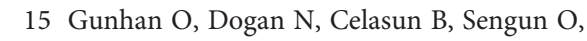
Onder T, Finci R: Aspiration cytology of oral cavity and jaw bone lesions. A report of 102 cases. Acta Cytol 1993;37:135-141.

16 Alam K, Maheshwari V, Haider N, Siddiqui F, Jain A, Khan A: Fine needle aspiration cytology (FNAC), a handy tool for metastatic lymphadenopathy. Internet J Pathol DOI: 10.5580/ $1 \mathrm{df} 3$.
17 Cinberg JZ, Silver CE, Molnar JJ, Vogel SE: Cervical cysts: cancer until proven otherwise. Laryngoscope 1982;92:27-30.

18 Granström G, Edström S: The relationship between cervical cysts and tonsillar carcinoma in adults. J Oral Maxillofac Surg 1989;47: 16-20.

19 Gourin C, Johnson J: Incidence of unsuspected metastases in lateral cervical cysts. Laryngoscope 2000;110:1637-1641.

20 Umudum H, Rezanko T, Dag F, Dogruluk T: Human papillomavirus genome detection by in situ hybridization in fine-needle aspirates of metastatic lesions from head and neck squamous cell carcinomas. Cancer 2005; 105 : 171-177.
1 Begum S, Gillison ML, Nicol TL, Westra WH: Detection of human papillomavirus-16 in fine-needle aspirates to determine tumor origin in patients with metastatic squamous cell carcinoma of the head and neck. Clin Cancer Res 2007;13:1186-1191.

22 Goldenberg D, Begum S, Westra W, Khan Z, Sciubba J, Pai S, Califano J, Tufano R, Koch $\mathrm{W}$ : Cystic lymph node metastasis in patients with head and neck cancer: an HPV-associated phenomenon. Head Neck 2008;30:898903 